\title{
ESTÁGIO E FORMAÇÃO NA PRÁTICA PEDAGÓGICA EM CRECHES PÚBLICAS ITALIANAS
}

\section{Agnese Infantino}

Faculdade de Ciência da Formação da Universidade de Milano-Bicocca

\section{Resumo}

O estágio universitário na formação dos futuros professores de creches pode ser uma ocasião importante para aproximar a formação da creche, a partir da centralidade da dimensão da prática. É no contato com a prática educativa que os estudantes podem desenvolver um pensamento reflexivo e crítico, competência fundamental no trabalho educativo, em particular com a primeira infância. As figuras da professora tutora de creche e do supervisor em sala sustentam o desenvolvimento de processos de aprendizagem e de conhecimento em que os estudantes desempenham um papel ativo, de protagonistas diretos na criação do saber. Em particular, merecem ser investigadas as dinâmicas da formação de cuja prática participam, em uma marcada interação mútua, estagiário e tutor. Esclarecer e conhecer melhor as modalidades dessa relação formadora daria uma contribuição ao valor da prática como dimensão constitutiva do saber e da formação em educação. $O$ artigo descreve um percurso de estágio universitário na Itália, destinado a estudantes que escolheram o âmbito da primeira infância, discutindo os principais nós críticos e os pontos fortes do planejamento educacional.

Palavras-chave: Educação Infantil; Formação docente; Estágio universitário.

Olh@ res, Guarulhos, v. 1, n1, p. 7-39, maio. 2013. 


\title{
TIROCINIO E FORMAZIONE SUL CAMPO NEI SERVIZI EDUCATIVI ITALIANI
}

\begin{abstract}
Riassunto
Il tirocinio universitario nella formazione dei futuri educatori può essere un'occasione importante per avvicinare la formazione in servizio e quella di base a partire dalla centralità della dimensione della pratica. E' nel contatto con la pratica educativa che gli studenti possono formarsi a un pensiero riflessivo e critico, fondamentale competenza nel lavoro educativo, in particolare con la prima infanzia. Le figure dell'educatrice tutor sul campo e del supervisore in aula sostengono lo sviluppo di processi di apprendimento e di conoscenza in cui gli studenti svolgono un ruolo attivo, di diretti protagonisti nella creazione di sapere. In particolare meritano di essere indagate le dinamiche della formazione sul campo alle quali partecipano, in un'interazione improntata alla reciprocità, tirocinante e tutor. Chiarire e conoscere meglio le modalità di questo rapporto formativo darebbe un contributo al valore della pratica come dimensione costitutiva del sapere e della formazione in educazione. L'articolo descrive un percorso di tirocinio universitario rivolto a studenti che hanno scelto l'ambito della prima infanzia discutendo i principali nodi critici e i punti forti del progetto formativo.
\end{abstract}

Parole chiave: Educazione della prima infanzia; Formazione in educazione; Tirocinio universitario.

\section{UNIVERSITY INTERNSHIP AND TRAINING IN THE FIELD IN EDUCATIONAL ITALIAN SERVICES}

\begin{abstract}
University internships as part of the training of future teachers offers an important opportunity to bring together in-service and basic training stemming from practice. Thanks to direct contact with educational practice, students can develop reflection and critical thinking, a fundamental aspect in education, especially with young children. The tutor in the field and the supervisor support the development of the learning processes in which the students play an active role, as direct protagonists in creating knowledge. It is worth investigating the dynamics of training in the field where they are active members, an interaction characterized by the reciprocity of the intern and the tutor. Clarifying and looking into how this training relationship works can contribute to the value of teaching practice as a dimension which constructs knowledge and training in education. The article describes university internship for early childhood education students and discusses the main critical aspects and strong points of the training project.

Key words: Early childhood education; Teacher Training; University internships.
\end{abstract}

Olh@ res, Guarulhos, v. 1, n1, p. 7-39, maio. 2013. 


\section{Premissa}

Nesta reflexão, procurarei relacionar duas dimensões estritamente correlacionadas: o estágio formativo e a formação na prática pedagógica da rede pública de creches italianas. Tentarei ilustrar o sentido desse enredo e do interesse heurístico que se segue.

O estágio é uma atividade formadora integrante dos diversos cursos de graduação universitária com finalidade de formação de base para educadores e professores. No âmbito do curso de Graduação em Ciências da Educação da Faculdade de Ciências da Formação, da Universidade de Milão-Bicocca ${ }^{1}$, o estágio se estrutura em diversas modalidades, dentre essas aquela da "Pequena Infância", e permite desenvolver uma experiência formadora na prática pedagógica dentro de uma unidade da rede pública ou domiciliar voltada às crianças pequenas (creches, creches integradas com a família, com a comunidade).

O estágio pode ser interpretado como um campo educativo "interno" dos percursos universitários e, neste caso, segue uma organização com a finalidade de cumprir o trabalho educacional, privilegiando os momentos e as dinâmicas ligadas principalmente aos atores internos ao mundo universitário: os docentes e, obviamente, os estudantes. A experiência nas creches, ligada às fases de participação - mais (ou menos) ativa e envolvente - dos estudantes nas dinâmicas educativas das creches públicas que os hospedam, constitui, com toda a riqueza do material educativo que se pode obter, o objeto de análise e da

1 Trata-se de um curso superior de três anos, que permite aos graduados conseguir um diploma como educadores e encontrar uma colocação profissional no setor de educação infantil, como creches e unidades domiciliares ou comunitárias, no território italiano. Segundo a lei da Região da Lombardia, de acordo com o Decreto da Junta da Região n. 20588 de 11/02/2005, para trabalhar nos serviços educacionais da infância (creches, berçários, maternais), não é requerido exclusivamente o diploma, são também considerados válidos os títulos de magistério ou técnico em ensino infantil. O percurso do estágio da modalidade "Pequena Infância" nasceu em 2004 e foi caracterizado por um progressivo aumento dos estudantes. Atualmente estão envolvidos aproximadamente noventa estudantes, duas dezenas de supervisores, e há, em curso, uma centena de acordos com entidades públicas e particulares que gestam creches e unidades domiciliares e/ou comunitárias. Durante este ano letivo serão feitas importantes reorganizações do percurso de estágio que aqui se descreve, em função da nova organização do curso superior ditado pelo Ministério da Instrução da Universidade e da Pesquisa da Itália.

Olh@res, Guarulhos, v. 1, n1, p. 7-39, maio. 2013. 
reflexão pedagógica conduzida em sede universitária.

No percurso educacional a que me refiro, a tentativa foi, por sua vez, de fazer algumas experiências na prática pedagógica das creches, não como objeto de uma reflexão a posteriori, mas como um sujeito em interação com o saber universitário; nessa perspectiva, foi pesquisada uma conexão mais estreita e dinâmica entre mundo e saber universitário e mundo e saber das creches. Isto é, foi colocada em discussão a ideia de um percurso de estágio fundado sobre dois momentos distintos: um sobre o momento em campo, na experiência direta em uma creche; e o outro momento, em uma aula dedicada à reflexão e ao discurso pedagógico.

Em linha com a tradição do pensamento ativo, pela educação ativa antes e consolidada depois com os desenvolvimentos do paradigma ecológico e sócioconstrutivista, o estágio é compreendido como um contexto formador teóricoprático, quebrando a implícita suposição de que o momento teórico deve prevalecer sobre o prático. Principalmente na educação da primeira infância, a “prática" educativa é saber, a experiência é pensamento; não se pode imaginar a educação de uma criança pequena separando ação e intencionalidade refletida, distinguindo claramente entre teoria (que tem lugar na sala de aula) e prática (que se faz nas creches) (INFANTINO, 2008).

Nesse sentido, o estágio foi interpretado dialeticamente como movimento de abertura necessária da formação universitária para o exterior, procurando ativamente interlocução e colaboração formativa com as creches públicas e com as educadoras de creche diretamente envolvidas no estágio na qualidade de tutoras. O resultado é uma complexidade do cenário educacional, pois os atores, nesse processo de estágio, são sempre, pelo menos, três: estudante, supervisor universitário, educadora tutora de creche interna na creche.

Dessa forma entendido, o estágio, que mantém certamente como sua principal finalidade a formação dos estudantes, torna-se, ao mesmo tempo, ocasião cultural para promover o saber e a cultura pedagógica sobre a infância nas creches, pois estimula a reflexão de parte das educadoras de creche que já

Olh@ res, Guarulhos, v. 1, n1, p. 7-39, maio. 2013. 
operam na área, envolvidas no estágio como tutoras dos estudantes, e também as envolve intelectualmente.

Dessa abertura decorre a conexão dos temas e das questões ligadas diretamente ao estágio universitário com os processos mais especificamente correlacionados à formação na prática pedagógica das creches.

Isto é, o fato de ativar e solicitar, a participação das educadoras de creche como tutoras dos processos educacionais do estágio por parte das educadoras de creche na qualidade de tutora levanta questões específicas ligadas ao profissionalismo e às competências formadoras específicas necessárias para que uma educadora de creche, com experiência de trabalho numa creche, possa aplicar as próprias competências profissionais num outro âmbito educativo: a formação de novas figuras educativas.

Abre-se, deste desse modo, todo um outro nível de reflexão ligado às dinâmicas e às condições (individuais, de grupo, da creche, institucionais) que devem ser pesquisadas, apoiadas e tratadas a tempo, para que a formação em campo realizada pela tutora seja realmente possível, viável e sustentável, quer por parte da educadora de creche, quer por parte da creche.

É neste ponto que emerge a importância da dimensão pedagógicoorganizacional das creches: o estágio (INFANTINO, 2002), nas suas implicações na prática pedagógica, torna-se um porto para as creches e para seus intricados fatos internos, que, somente na presença de algumas circunstâncias, podem, de fato, oferecer-se como campo de formação para os estudantes; e, ao mesmo tempo, de autoformação para as educadoras de creche. Visto por essa perspectiva, o estágio evidencia um âmbito formativo com elevadas potencialidades, não fechado em si mesmo, colocado no cruzamento de múltiplas dimensões, caracterizado por processos de várias naturezas: não só formativa, mas também institucional, organizacional e, não menos importante, de políticas das creches; ao mesmo tempo, emergem questões heurísticas amplas, relativas às finalidades e aos objetivos educacionais do estágio para os estudantes e para as figuras das educadoras tutoras de creche, por exemplo,

Olh@ res, Guarulhos, v. 1, n1, p. 7-39, maio. 2013. 
ligadas às dinâmicas formadoras mais eficazes para apoiar processos de aprendizagem e formação, fundamentadas na direta participação dos estudantes na prática pedagógica das creches.

Se a formação acontece de modo significativo nas creches, facilitada pela intervenção das educadoras tutoras de creche, então é importante, por um lado, questionar as modalidades mediante as quais se desenrola efetivamente a relação formativa entre estagiário e tutora; e, por outro lado, pôr em prova as especificidades e as condições dessa particular forma de aprendizagem, na qual, com dinâmicas específicas e diversificadas, aprende tanto o estudante, quanto a educadora tutora de creche que o auxilia (AGLIATI e INFANTINO, 2010).

\section{O sistema formativo e as escolhas estruturais}

Antes de expor de modo detalhado a estrutura organizacional e o projeto formativo do percurso do estágio, será necessário indicar alguns elementos relativos aos pressupostos pedagógicos subjacentes.

O estágio, articulado no segundo ou terceiro ano da graduação, estrutura-se complexamente em duzentos e cinquenta horas e consente dez créditos formativos universitários que, portanto, ajudam a completar o percurso formativo dos estudantes. O primeiro e o segundo ano de estágio se desenvolvem com objetivos e articulações específicas, no âmbito de um planejamento educacional abrangente, e respeitam algumas escolhas estruturadas subjacentes, relativamente a:

- grupos estabelecidos de estudantes

- figura do supervisor universitário

- coordenação e planejamento conjuntos

Os grupos de estágio são formados no segundo ano e permanecem iguais também no terceiro. Criar um grupo estável é importante. O grupo dos estudantes, que varia em torno de vinte componentes, torna-se a sede para partilhar pressupostos e referências pedagógicas, para debater ideias e experiências conduzidas em contextos que podem também ser muito diferentes

Olh@ res, Guarulhos, v. 1, n1, p. 7-39, maio. 2013. 
entre eles em territorialidade sociocultural, em tipologia de creche. É uma dimensão coletiva, mas, para as contidas extensões quantitativas, não parece ser dispersiva e generalizante como, por vezes, são as aulas na universidade quando lotadas. Podem emergir e ter espaço modalidades diferentes da construção do conhecimento e saberes a partir de uma visão plural da realidade das creches, dos estilos educativos observados, das leituras realizadas pelos mesmos estudantes, que podem ser discutidas, entendidas, comparadas e analisadas.

A estabilidade do grupo e a possibilidade de se encontrar e se reencontrar, compartilhando um caminho temporal estendido, propiciam condições favoráveis não somente para confrontar complexos conteúdos educativos, que implicam evolução e desenvolvimento no tempo, mas também para chegar ao progressivo conjunto de um método de trabalho, com a finalidade de individuar e de definir a natureza dos conteúdos e dos problemas educativos com os quais se entra em contato na prática pedagógica das creches.

Os estudantes que estão se formando para, no futuro, serem profissionais da educação no âmbito da primeira infância precisam treinar o olho e a mente para saber compreender e investigar de maneira crítica as áreas relevantes, quando, por exemplo, se observa uma situação educacional; muitas vezes, num debate de um caso educativo, fundamental para a formação, parece mais emblemática a questão relativa ao método de análise do que o conteúdo específico envolvido num único episódio. Assim definido, o trabalho de análise envolve não somente um único estudante, mas todo o grupo, e se criam condições para uma abordagem analítica da realidade baseada no debate e na visão plural e coletiva dos problemas, como depois será (ou deveria ser) no trabalho efetivo nas creches, onde é importante a capacidade de ver um mesmo problema por vários pontos de vista, para considerar as hipóteses de intervenção em uma gama de múltiplas possibilidades.

Numa situação protegida, como resulta das pressões reais do trabalho educativo na creche, os estudantes podem experimentar algumas dinâmicas que depois caracterizarão a vida dos grupos de trabalho: achar a palavra e os modos para

Olh@ res, Guarulhos, v. 1, n1, p. 7-39, maio. 2013. 
experimentar o próprio ponto de vista; dialogar em torno de um objeto comum, harmonizando visões diversas; fornecer uma contribuição à discussão; escutar e compreender o ponto de vista expresso pelos outros; aceitar e enfrentar um conflito. O grupo pode, portanto, ser sede preciosa para aprendizagens e metaaprendizagens.

O fato de o supervisor universitário também ser o mesmo durante os dois anos de estágio facilita o estabelecimento de uma relação de entendimento mútuo e permite individualizar, o quanto possível, as atenções na formação.

Outra importante escolha se refere na à figura do supervisor, que não é um docente universitário, mas um profissional experiente em creches, selecionado por sua experiência na prática pedagógica. Supervisores são coordenadores de creches, de formadores e de educadoras que operam nas instituições para a primeira infância e estão familiarizados com os temas, as questões e as áreas sensíveis do trabalho educativo, porque lidam diretamente com tudo isso em seu trabalho. O saber que se busca ativar no âmbito da supervisão não é abstrato e teórico, mas é o saber da experiência educativa e pedagógica para os fatos e os problemas educativos, colocando em constante interação os temas teóricos com os vínculos institucionais, as necessidades educativas com organizações conjuntas, as questões individuais com as visões sistemáticas da complexidade do trabalho em rede; procura fazer dialogar abordagens metodológicas, linguagens e conhecimentos que têm diferentes proveniências disciplinares e precisam de uma interconexão dinâmica no trabalho educativo. Mais do que propor modelos e paradigmas predefinidos, o supervisor pede aos estagiários a reflexão e a problematização da realidade observada nas creches; ajuda a colocar questões e a formular hipóteses para orientar por meio de uma compreensão não superficial das dinâmicas educativas; orienta um trabalho de observação cuidadoso e uma atenta documentação do material de variada natureza levantada nas creches. Em suma, oferece um suporte teóricometodológico totalmente específico, que não se sobrepõe, de forma alguma, ao modo de trabalho educacional desenvolvido pelos docentes ao longo das aulas

Olh@ res, Guarulhos, v. 1, n1, p. 7-39, maio. 2013. 
na universidade. Nesse sentido, o supervisor não organiza os encontros como se fossem uma aula de escola; estimula o grupo por meio de dinâmicas de ativa e direta participação, acolhendo e estruturando formas legíveis o material educativo que os próprios estagiários levantaram durante sua permanência nas creches.

Os assuntos e temas específicos de que cada grupo trata variam muito; portanto, cada supervisor desenvolve um próprio itinerário formativo, também em função das características e das necessidades de aprendizagem do grupo de estudantes com o qual trabalha, tendo em conta as diretrizes e as orientações do projeto educacional comum, desenvolvido e compartilhado por todos os supervisores durante reuniões periódicas de coordenação ao longo do ano.

A outra dimensão fundamental na qual, de fato, se investe muito é relativa à coordenação dos supervisores. O planejamento do percurso do estágio é âmbito de debate e de discussão em grupo e, ao longo do tempo, conduziu à definição de propostas e estratégias operacionais que passaram por mudanças e reajustes. Os tempos e a escansão temporal das propostas; a tipologia das ofertas; a abordagem e a orientação formativa, além, obviamente, dos objetivos e dos meios de intervenção - todos esses elementos projetados são âmbito de discussão e de comparação para definir percursos educacionais compartilhados e comuns, às vezes alcançados no final de debates difíceis, os quais, por parte dos supervisores, são prioridades expressas e escolhas metodológicas diferentes.

Um tema que, muitas vezes, reacende discussões é, por exemplo, o valor e o sentido educacional da observação. Alguns supervisores compartilham a ideia da observação como método de trabalho essencial e consideram importante orientar nessa direção o olhar dos estagiários desde o primeiro contato com as creches; outros atribuem menor valor à observação, primeiramente vista em termos instrumentais, e apontam o envolvimento dos estagiários na dinâmica das creches para obter material para análise, também de natura reflexiva. Outro tema que acalora o debate é o "objeto" a partir do qual começa o percurOlh@ res, Guarulhos, v. 1, n1, p. 7-39, maio. 2013. 
so de supervisão: alguns supervisores acreditam que devam estar relacionados os contextos educativos em sua materialidade e em seu valor simbólico, as relações educativas e as situações diretamente observadas na prática pedagógica do trabalho educativo; outros pensam que seja prioritária a explicitação das ideias, das prefigurações, das expectativas dos estagiários, para encaminhá-los depois a um contato mais consciente com a realidade das creches.

Ao longo desses debates entre supervisores, assumem forma visões do trabalho educacional e de supervisão que remetem a pressupostos pedagógicos e a histórias profissionais e biografias educacionais diferentes, das quais emergem importantes reflexões e questionamentos jamais previstos, relativos aos modos e às formas mais eficazes nos processos de formação e de aprendizagem dos estudantes estagiários.

O trabalho de planejamento que acontece na coordenação é extremamente rico e intelectualmente desafiador - não é, com certeza, um exercício de rotina burocrático: o compartilhamento metodológico e estratégico que se chega a construir é o êxito nunca definitivo de animadas e preciosas discussões que tornam vital esse trabalho e corroboram, mais uma vez, o quanto é crucial e insubstituível a dimensão social nos processos educacionais.

Especificamente, é essencial salvaguardar um espaço de debate aberto e dialético entre supervisores, já que, por sua vez, são os mediadores e facilitadores das discussões e dos debates nos grupos dos estagiários.

\section{O primeiro ano de estágio: para o trabalho educativo nas creches}

O primeiro ano de estágio (que para os estudantes é o segundo ano da graduação) é denominado "propedêutico", por sua natureza introdutória e pela progressiva aproximação do conhecimento do trabalho educativo nas creches. Para responder a esse objetivo, o percurso do estágio é articulado em cinquenta horas, subdivididas em reuniões com a supervisão, visitas às creches e trabalho individual.

Olh@res, Guarulhos, v. 1, n1, p. 7-39, maio. 2013. 
Os estudantes geralmente não têm consciência do que são as creches e da complexidade do trabalho educativo que as caracteriza; de certo modo, eles gostariam de "mergulhar" o mais rápido possível nesse mundo, mas, ao mesmo tempo, demonstram receio e sentem-se despreparados. Por esses motivos, o primeiro ano de estágio facilita os variados níveis de contato entre estudantes e creches: um primeiro ocorre quando o supervisor acompanha seu grupo para visitar duas ou três creches; uma outra modalidade de contato é possível ao longo das reuniões de supervisão, das quais participam educadoras especialistas; e, finalmente, estabelece-se um primeiro contato com as creches, desta vez de caráter individual, com o trabalho de "mapeamento do território", ou seja, quando os estudantes exploram (virtualmente e fisicamente) a variedade de creches em sua região.

O percurso de estágio começa quando, depois de formado o grupo e ocorrido pelo menos um primeiro encontro para reconhecimento, o supervisor acompanha uma visita de seu grupo em uma unidade da rede pública ou domiciliar voltada às crianças pequenas (creches, creches integradas com a família, com a comunidade), fora do horário de funcionamento, ou seja, quando as crianças não estão, ou nos ambientes onde elas não estão presentes. Essa é, muitas vezes, a primeira vez que os estudantes entram em uma creche e, com certeza, em uma comunidade. As expectativas e as emoções são muito grandes. Às vezes, esse momento é precedido por um encontro com uma educadora ou coordenadora da creche, que introduziu os temas e as questões relacionadas especificamente ao trabalho no contexto educativo que será depois visitado.

A ideia básica é permitir aos estudantes entrar em contato com uma creche e com um trabalho educativo em uma modalidade "guiada". Ou seja, dentro de um percurso pensado metodologicamente para evidenciar e tornar particularmente visíveis alguns elementos do contexto organizacional e educativo sobre o qual se quer direcionar a atenção e que, feito de forma diferente, correriam o risco de ser ofuscados por todos e ignorados por um olhar ingênuo. Ao visitar os ambientes da creche, chama-se a atenção, por exemplo,

Olh@ res, Guarulhos, v. 1, n1, p. 7-39, maio. 2013. 
ao que está pendurado nas paredes para decorar e para comunicar; à quantidade e à tipologia dos materiais à disposição das crianças; à localização espacial dos objetos.

O espaço fala, revela, induz a compreender as ideias implícitas e as escolhas deliberadas feitas por quem o predispôs; conta os pensamentos que norteiam o estar dos adultos com as crianças; permite imaginar os modos como crianças e adultos compartilham o tempo e o espaço. Expressa um planejamento e um pensamento educacional que permitem, se quiser, reconhecer a cultura pedagógica daquela creche.

Visitados os ambientes, há depois um tempo dedicado ao debate com o coordenador e com uma ou mais educadoras da equipe. Esta é a ocasião para fazer perguntas, pedir mais detalhes e explicações - em suma, recolher, de modo direto, o pensamento daqueles que operam na creche, ouvindo-os contar episódios significativos e emblemáticos. A visita permite ver ao vivo uma creche, debater com as educadoras, experimentar metodologicamente uma modalidade de conhecimento de uma creche, o que será útil logo mais, quando for necessário organizar algumas visitas individuais durante o trabalho de mapeamento.

O outro importante momento do percurso do primeiro ano refere-se aos encontros organizados com educadoras especialistas que, em função da experiência profissional maturada, são importantes interlocutores para descrever de maneira profunda algumas dimensões constitutivas do trabalho educacional.

Nessas ocasiões, o relato toma formas muito diferentes, traçando as especificidades biográficas e profissionais das pessoas envolvidas. A intenção é fazer emergir, por meio das palavras, a narração de quem o vive cotidianamente, a complexidade do trabalho educacional, contextualizando-o no quadro do sistema organizativo, legislativo, institucional, político em que se põe. Um dos primeiros objetivos com o qual se mede o percurso do estágio é, a bem da verdade, trazer, em primeiro lugar, aquelas dimensões normalmente ig-

Olh@ res, Guarulhos, v. 1, n1, p. 7-39, maio. 2013. 
noradas e implícitas da vida das creches, mas que, embora de maneira escondida, influenciam e, às vezes, determinam os eventos educativos mais visíveis - e, justamente por isso, devem ser conhecidas.

A tentativa é de constatar como o trabalho educacional não consome a relação (também absolutamente central) da educadora de creche com a criança; essa percepção implica um complexo de outros níveis de conhecimento e forma de gestar (sempre que possível!). Contribui também para este objetivo o trabalho individual de mapeamento do território para o qual cada estagiário é designado, a fim de averiguar a oferta de creches na área geográfica em que reside.

Não se trata de um simples "censo", mas de um profundo monitoramento das creches existentes, que serão catalogadas por tipologia, formas de gestão, características do projeto. Algumas serão também visitadas. Pouco a pouco, os estudantes recolhem documentos e informações sobre as creches, o que fornecerá ao supervisor material para analisar e compartilhar com o grupo. Com a confluência de todas essas fontes de conhecimento (as visitas nas creches, os encontros com as educadoras especialistas, a revelação da variedade das creches na região), o grupo, sob a orientação do supervisor, dispõe de um material amplo e diversificado, que fala da experiência educacional concreta nas creches e permite conduzir um trabalho de análise e debate que propicia aos estagiários construir e partilhar o saber e o conhecimento.

Torna-se possível visualizar algumas especificidades e peculiaridades que caracterizam as creches e o trabalho educacional, pondo a intervenção profissional da educadora de creche no ápice do projeto pedagógicoorganizacional e da tipologia da creche onde opera. Recolhem-se linhas transversais e de especificidade no trabalho educacional feito, por exemplo, em uma creche e em uma comunidade, recuperando uma distância crítica que ajuda os estudantes na escolha relativa ao percurso do próximo ano, que os verá diretamente inseridos na vida cotidiana de uma creche.

Ao final desse primeiro ano, o supervisor estimula os estagiários a elaborar individualmente um relatório final que sintetize e discuta as fases mais incisivas Olh@ res, Guarulhos, v. 1, n1, p. 7-39, maio. 2013. 
do percurso feito e a reelaborar uma reflexão pessoal.

\section{O segundo ano: o estágio na creche}

O tema dominante do segundo ano de estágio é justamente a inserção em uma creche. São muitas as passagens que precedem e acompanham este momento que, nas intenções do projeto, se caracterizaria por um progressivo envolvimento dos estudantes no cotidiano da creche, mas nem sempre é assim. Se, realmente, os tempos e as modalidades de desenvolvimento do trabalho educacional no primeiro ano de estágio são substancialmente definidos pelo grupo dos supervisores, em contrapartida, ao longo do segundo ano, o quadro se alarga e fica mais complexo, pois entram em cena as creches, que definem suas datas, prioridades e condições de colaboração.

A inserção de um estagiário no interior de uma creche, de um serviço integrativo ou de uma comunidade é um processo delicado, de predisposição de vários níveis, com providências, seja de natureza administrativo-institucional (estipular uma convenção; fornecer um seguro; estabelecer um contato operativo com os responsáveis), seja de natureza de projeto e relacional (informar e compartilhar no grupo educativo as novas responsabilidades; estruturar um plano de trabalho; acordar os tempos de dedicação de cada estagiário).

Os modos e os tempos com os quais se executa concretamente o estágio na prática pedagógica são responsáveis, portanto, pelo equilíbrio entre as exigências da creche e aquelas do projeto universitário. Algumas creches investem muito nessas experiências, trançando potencialidades formadoras e de desenvolvimento em prol dos funcionários (da própria creche) e expressam grande disponibilidade e adesão às propostas colocadas por eles; outras creches lidam com esforços organizacionais internos ou simplesmente menos orientados em formas de abertura para o exterior e exprimem uma disponibilidade mais limitada e vinculada. Isso se traduz em fatos de muitas maneiras: em alguns casos, as creches não definem uma figura de tutor, mas atribuem essa função ao

Olh@ res, Guarulhos, v. 1, n1, p. 7-39, maio. 2013. 
coordenador, que, muitas vezes, opera em outras creches e não é presente no cotidiano da creche onde, por sua vez, o estagiário tem sua experiência; ou também se definem alguns períodos de disponibilidade muito concentrados, que impedem uma diluição do estágio no tempo; ou, ainda, opta-se por uma imersão imediata do estagiário na gestão de algumas situações com as crianças; ou também, ao contrário, o colocam sempre à distância, em posição de observador. Essas questões, que poderiam parecer marginais, têm um impacto profundo no andamento e nos êxitos do estágio, e os estudantes, com o tempo, tornam-se conscientes.

Por todas essas razões, o objetivo do primeiro período de inserção é ligado ao conhecimento da implementação pedagógico-organizacional da creche. Os estagiários são incentivados a adotar um posicionamento que poderíamos definir antropológico, ao observar, como "estrangeiros", a realidade e a cultura nas quais foram inseridos, para se questionarem sobre aquilo que é dado como óbvio e desconsiderado por aqueles que são parte da creche e partilham a cultura educacional. Os horários, os arranjos de acolhimento das crianças na parte da manhã, a cor das paredes, a quantidade de jogos, os turnos do pessoal: é a fase em que é lícito questionar e perguntar de tudo, para poder entrar em contato com a cultura da creche que recebe o estudante. Isso significa traçar sinais, símbolos e expressões do pensamento e da cultura pedagógica; documentar as atividades diárias para perceber as escolhas de referência educativas; observar as relações entre todas as pessoas presentes na creche: o levantamento apurado desse material fornece elementos úteis para compor um primeiro quadro de conhecimento indispensável para encontrar uma colocação coerente no sistema. A educadora tutora de creche, a partir desse ponto de vista, desenvolve um papel insubstituível e imprescindível, fornecendo todas as informações e indicações (também aquelas estritamente materiais e logísticas) necessárias para que o estagiário possa fazer seu trabalho.

Estas primeiras fases de exploração na prática pedagógica acontecem, na realidade, de maneiras muito diferentes, em função das características e das

Olh@ res, Guarulhos, v. 1, n1, p. 7-39, maio. 2013. 
competências de cada estagiário ou das efetivas disponibilidades das creches, que, algumas vezes, envolvem os estagiários, desde o começo, em experiências diretas, na prática pedagógica com as crianças. É, principalmente, o caso das comunidades. Nesses casos, manter uma atitude distanciada e um olhar de observação é quase impossível, e se faz necessário, então, capacitar os estagiários para um intenso trabalho de documentação a posteriori, que resguarde a possibilidade de conservar o caminho e a memória das situações e das dinâmicas educativas das quais participaram. Além disso, para um estudante inexperiente, manter em foco essa dupla atenção não é, de fato, simples; e é sempre muito alto o risco de serem oprimidos e engolidos no centro dos problemas e das questões educativas e relacionais cujo significado e abrangência seriam difíceis de se compreender plenamente, por causa de sua inexperiência.

De natureza oposta são as dificuldades que devem ser afrontadas por quem faz o estágio em creches excessivamente cautelosas, que nunca consentem aos estagiários enfrentar situações de maneira direta na prática pedagógica da participação. Entre esses opostos extremos, há toda uma gama variada e majoritária de práticas de estágio, em que, gradualmente, os estudantes entram nas creches, se ambientam e, progressivamente, se aproximam do trabalho da educadora tutora de creche, para tentar enfrentar, de forma direta, algumas situações sob o olhar atento do tutor.

Ao longo dessas experiências, os estagiários são, de qualquer forma, encorajados a envolver-se num constante trabalho de observação. Por que essa ênfase no momento da observação? A observação durante o estágio não finda na elaboração de protocolos de observação para um simples exercício técnico, mas é proposta como método de trabalho: pensa-se na observação como técnica, então, esta se concentra nas estratégias e nos instrumentos que tornam possível o levantamento dos dados, ativando um processo substancialmente finalizado para a elaboração de material para observação; pensa-se, também, que a observação, enquanto método de trabalho, se refere a um processo articu-

Olh@ res, Guarulhos, v. 1, n1, p. 7-39, maio. 2013. 
lado em que é envolvida a educadora de creche com seu pensamento e com suas modalidades de intervenção nos contextos educacionais. Ela parece estar relacionada com as crianças e com a realidade de que faz parte, para reconhecer o ponto de vista dos outros; para fazer hipóteses e projetar intervenções, em sintonia com as necessidades e as exigências das pessoas com as quais se relaciona; para operar uma efetiva descentralização, em benefício das crianças e dos adultos que se utilizam da creche.

A observação como método implica uma atitude educativa fundamental, baseada na capacidade de pensar e refletir, enquanto os estagiários se envolvem como atores na ação em curso; sustenta uma atitude de lúcida presença profissional descentralizada, para propiciar comportamentos e intervenções educativas que, fundamentados na escuta e na compreensão profunda daquilo que está acontecendo no contexto e com as outras pessoas, possam ser realmente um benefício para as crianças.

Nesse sentido, a observação não é exatamente uma técnica, mas um método de trabalho e, nessa perspectiva, é proposta aos estudantes. Se, portanto, a fase de início do estágio se abre com um período de conhecimento e observação da realidade da creche, de fato, o trabalho e a ação de observar não deveriam cessar nunca: precisam continuar a ser exercitados e consolidados ao longo da experiência do estágio, também graças à troca com a educadora tutora de creche.

Os protocolos observados tornam-se, na verdade, material de trabalho compartilhado pelo estagiário e pelo tutor que, a partir deles, realizam trocas e debates, aprofundam aspectos da vida cotidiana educacional, sobre a qual não seria possível debater enquanto a educadora de creche está ocupada com um grupo de crianças.

A constante troca e o diálogo sobre o trabalho educacional, sobre o que se pode falar, sobre por que razão existe uma documentação oferecem ao estagiário o terreno de base para experimentar diretamente na prática pedagógica, conduzindo uma proposta ou um momento do dia com um grupo de crianças. A

Olh@ res, Guarulhos, v. 1, n1, p. 7-39, maio. 2013. 
possibilidade de experimentar e de pôr em prova; de tentar fazer e de ser diretamente responsável por uma situação educativa com as crianças é muito importante para o estudante, que é posto em situação de verificar materialmente e emotivamente o que significa tomar conta de uma criança pequena, como se sente ao trocar uma criança, como se comporta durante uma disputa e/ou briga entre crianças. Em suma, precisa tentar, realmente, fazer o trabalho educacional que, até aquele momento, apenas leu, estudou e observou.

Tentar "fazer" ao longo do estágio significa envolver-se em situações educativas privilegiadas, por estar em um contexto protegido, sem o peso direto da responsabilidade e dos riscos nos confrontos entre as crianças, pois a responsabilidade é, a bem da verdade, da educadora tutora de creche, que mantém a titularidade completa, está presente e observa as intervenções feitas pelo estagiário. Se, de fato, nas fases precedentes, o estudante pode observar as modalidades de intervenção da educadora tutora de creche e das outras educadoras da creche, agora a situação é inversa: é a educadora tutora de creche que observa o estagiário em ação, e também sobre essas experiências ocorrem a comparação e a avaliação. Essa alternância dos papéis de ator e observador fundamenta os pressupostos para um relacionamento formador caracterizado pela reciprocidade de olhares, atenções, pensamentos.

Enquanto, nas creches, os estudantes estão engajados em um processo de conhecimento direto do trabalho educacional, durante as reuniões de supervisão, toda a riqueza e a complexidade dessas experiências se tornam objeto de análise e discussão em grupo, com a orientação do supervisor. A educadora tutora de creche pode fornecer indicações e aprofundamentos educativos relativos a contextos específicos e situacionais, e o supervisor expande a visão; solicita os debates; estimula o pensamento através de ligações teórico-práticas; chama a atenção aos planos implícitos e menos evidentes; sustenta a construção de uma prospectiva analítica e crítica. A supervisão, a partir da análise do caso, opera o nível de conceituação e de representação, mediante categorias educativas que possam ajudar a compreender os eventos

Olh@res, Guarulhos, v. 1, n1, p. 7-39, maio. 2013. 
ocorridos e vividos pelos estudantes e atribuir significado a eles.

É evidente o quanto são turvos os limites entre o âmbito da supervisão em sala e aquele da experiência na prática pedagógica, tendo ambos como "objeto" o trabalho educativo explorado, embora com abordagens e campos de pertinência específicos. Aqui se impõe, em toda sua complexidade, o tema do valor e do significado da dimensão da experiência em educação e na formação. E, nesta óptica, o papel desenvolvido pela educadora tutora de creche é delicado.

\section{O papel da educadora tutora de creche}

Enfatiza-se de modo unânime a centralidade de experiência na formação na educação - penso o quanto isso é relevante na educação das crianças pequenas - e, ao fazê-lo, a partir das reflexões de Dewey (1929), se afirma o valor dos "fatos educativos", ponto de início e de retorno para cada reflexão e indagação sobre a educação. Mas, na realidade, a experiência e o pensamento que sublinham a centralidade do momento experimental em educação, são um terreno extremamente vasto, habitado por uma pluralidade de ideias, paradigmas e interpretações. Logo, é necessário ir além da afirmação de uma genérica centralidade da dimensão experimental, para explicitar, de modo articulado, o papel e as funções da educadora tutora de creche.

Nesse sentido, é necessário referir-se a diferentes níveis de reflexão: um primeiro remete ao significado da experiência relativa ao profissionalismo da educadora tutora de creche, que é (ou deveria ser) capaz de desenvolver funções tutoriais, por ser figura "especialista", que tem consciência e padronização das dimensões múltiplas com que se articula na experiência o trabalho educacional. É uma educadora de creche que maturou uma sólida experiência de trabalho na prática pedagógica e poderia ser definida como uma "profissional reflexiva" (SCHÖN, 1987), capaz de exercitar a própria expertise também em uma declinação formadora nos debates de estagiários inexperientes. No perfil da educadora tutora de creche não são relevantes sua idade, o tempo de casa ou sua formação, e, sim, as modalidades individuais e originais do todo, mediante as

Olh@res, Guarulhos, v. 1, n1, p. 7-39, maio. 2013. 
quais ela tem e sabe ter experiência em seu trabalho educacional. Pode, portanto, dispor-se, não tanto como tutora, mas como modelo para um estagiário, para que, quando vier a atuar, ele possa "ter experiência" e não somente fazer ou repetir mecanicamente, sem pensar, as ações observadas, colocadas em ato por outros.

Outro nível de reflexão acerca da centralidade da experiência refere-se, portanto, às modalidades mediante as quais os estagiários se formam na experiência: o tutor não ensina a eles como fazer o trabalho educacional e não os confina a uma posição passiva de recepção de conteúdos e técnicas - ele os faz observar e aproximar-se do trabalho; sustenta e estimula nos estudantes processos de curiosidade, abertura, pesquisa, questionamento do momento que, como observa Schön (1987), significa "procurar alguma coisa", implica a capacidade de reconhecer o que se está procurando. Mas ao estudante, no início, falta essa capacidade de reconhecer o objeto de sua pesquisa.

A experiência é, ao mesmo tempo, objeto e método da formação; a condição em que o estagiário desenvolve um papel ativo, deseja aprender e aceita sair no desconhecido, pôr-se em jogo, para adquirir um conhecimento que não é predefinido em um saber codificado, mas que se cria pouco a pouco, a partir do contato pensado com a realidade e com outros sujeitos do contexto em que se opera.

O outro aspecto que merece reflexão refere-se à natureza do saber educacional, saber composto, saber da experiência, em que, ao lado dos componentes definidos e reconhecíveis em seus fundamentos teóricos, convivem dimensões mais sutis, relacionadas a aquisições maturadas, experimentando e tentando fazer; ligadas a processos de descoberta e de pesquisa na prática, e não de aquisição e conhecimento de dados preexistentes. Muito do trabalho educativo (e da aprendizagem) provém de processos heurísticos e não pode ser objeto de ensino ou de pura transmissão de conhecimento nos debates de outros (COSENTINO e SANTINI, 2008).

Ter experiência na prática pedagógica, em um contexto protegido e com a

Olh@ res, Guarulhos, v. 1, n1, p. 7-39, maio. 2013. 
orientação de um supervisor, significa, para os estagiários, participar de um processo formador em que será possível aprender, ativando-se e medindo-se no fazer pensado; será possível compreender, observando e indagando-se.

A educadora tutora de creche desenvolve um papel complexo, ocupando-se, antes de mais nada, de garantir as condições de contexto complexas, para que esses processos de aprendizagem possam ter lugar no cotidiano da creche; e aproximando, sustentando o desenvolvimento desse percurso radicado na experiência.

É dever da educadora tutora de creche conhecer o estagiário e estabelecer um contato privilegiado que acompanhe no tempo sua permanência na creche; oferecer-lhe a possibilidade de estar presente nos vários momentos do dia educativo, para observar também educadoras e grupos de crianças diferentes. Oferecer-lhe, ainda, a oportunidade de participar de diferentes ocasiões de trabalho (reuniões da equipe educativa e de algumas educadoras da creche) ou de reuniões com os pais. Especificamente, depois o estagiário e tutor compartilham momentos de reflexão do dia educativo observado e documentado no diário de estágio que, pouco a pouco, o estudante elabora.

Pensando nas funções desenvolvidas pela tutora, emergem claras linhas de continuidade com as funções tutoriais feitas no âmbito dos processos de scaffolding $^{2}$ (WOOD, BRUNER e ROSS, 1976) e, em geral, nas formas de aprendizagem guiada (ROGOFF, 1990). As funções tutoriais, assim como são definidas por Bruner, preveem que o mais especialista se envolva na tarefa do estagiário, reduza o grau de dificuldade, mantenha a orientação da atividade em referência aos objetivos, marque as características determinantes, controle a frustração, mostre a ação.

A educadora tutora de creche não efetua de maneira deliberativa e sis-temática exatamente a complexidade de todas essas funções (das quais geralmente não está totalmente consciente); todavia, em muitas situações, as educadoras tutoras

2 Processo no qual um adulto apoia a criança a solucionar uma tarefa e/ou processo em que, para que uma tarefa seja cumprida, é necessário um trabalho em conjunto (nota do tradutor).

Olh@ res, Guarulhos, v. 1, n1, p. 7-39, maio. 2013. 
de creche mais experientes têm ciência da importância de se colocarem como referência clara na experiência que o estagiário está fazendo na prática pedagógica. A seguir, o modo como uma tutora descreve essa particular relação formadora:

Eu, das minhas crianças, notava várias coisas, os passos, as melhorias e me perguntava se a estagiária também conseguia notá-los, por isso às vezes lhe perguntava: "Você viu o que aconteceu?". Por exemplo, no jogo com a farinha, quando elas se enchem, basta que eu dê um funil e o jogo recomeça... depois me dei conta, com o passar do tempo, que, quando eu notava uma coisa, a olhava e os nossos olhares se cruzavam e ela me dizia que tinha notado. Depois de um segundo lhe perguntava: "O que você viu? O que você notou?". Cruzar os olhares no nosso trabalho é muito importante. ${ }^{3}$

Essas palavras focalizam com extrema eficácia dois elementos que, em particular, me parecem fundamentais neste tipo de formação na prática: a centralidade das dinâmicas que têm as crianças como protagonistas e a qualidade da interação estagiária-tutora. Compreender o que ocorre entre as crianças, como acontece o desenvolvimento, em quais formas evoluem as interações sociocognitivas e afetivas, com quais estratégias as crianças aprendem - são essas as dimensões e as modalidades nas quais os adultos se baseiam para o trabalho educacional. O estagiário próximo a um tutor especialista entra em contato não somente com o mundo das crianças, mas também com a perspectiva educativa - por isso, cultural, social, organizacional e política - da abordagem à infância e ao trabalho expresso, mais ou menos explicitamente e conscientemente, da educadora tutora de creche.

Tal dinâmica pode resultar de extrema vitalidade intelectual, principalmente quando, como no depoimento acima transcrito, estagiária e tutora conseguem estabelecer um vínculo de compreensão e de comunicação realmente mútua. Nessas condições, os olhares convergem, por remeter a um espaço de palavra sucessiva, dedicado à expressão de pensamentos, ideias e intuições emergentes dos fatos ocorridos entre/com as crianças. O tutor não tem, portanto, o dever de adquirir técnicas ou práticas de intervenção, mas precisa observar, compreen-

3 Estas reflexões e as outras que se seguem foram recolhidas das educadoras tutoras de creche que fizeram parte dos seminários da universidade estruturados no âmbito do percurso do estágio.

Olh@ res, Guarulhos, v. 1, n1, p. 7-39, maio. 2013. 
der, discutir com o estagiário as dinâmicas educacionais que envolvem as crianças; nesse sentido, cada vez se cria uma forma de conhecimento e um saber original e específico, contextualizado e situado, que pode ser a condição em que estagiário e tutor assimilam significado, transformam em palavra os fenômenos educacionais notados e, para eles, relevantes. Somente estando na prática pedagógica ao lado de uma educadora tutora de creche especialista, é possível ter experiências formadoras desse tipo.

A partir dessas experiências formadoras, contudo, o tutor também aprende. Aprende, segundo dinâmicas de autoformação, quando, por exemplo, a atividade de observação do estagiário propõe - reativado e atualizado graças ao estagiário - um método de trabalho que talvez tenha se tornado rotineiro ou tenha sido totalmente transformado, ao longo do tempo, pelo grupo educativo. Também aprende, quando as perguntas do estagiário implicam na pesquisa das razões que sustentem os comportamentos e as escolhas realizadas; e, para certas questões, constringem a tornar explícito um complexo de alternativas de fundo sobre as quais, entre as colegas, não se fala mais ou não se fala frequentemente. Explicar ao estagiário o porquê de certas atitudes, de certos materiais oferecidos ou negados às crianças; de certas modalidades adotadas nas interações com as crianças ou com as colegas é um bom exercício, que implica o conhecimento do próprio agir educativo, considerando por conhecimento uma disposição reflexiva e crítica à análise dos fatos educativos (BRAGA, 2009), que leva a descentralizar-se e a rever-se, em determinada situação, percorrendo $a$ posteriori os fatos e as dinâmicas educativas com um olhar voltado à interpretação e à atribuição de significado.

Para as educadoras tutoras de creche, além disso, são previstas algumas reuniões para projetar e debater com os supervisores ${ }^{4}$. E delas espera-se também que procurem ocasiões para refletir sobre sua experiência tutorial no

4 Ao longo do ano foram realizadas três reuniões dedicadas à projeção e à avaliação do trabalho educativo, das quais participaram tutores e supervisores, que, nessas ocasiões, compartilham ideias e debatem a respeito de conteúdos, instrumentos e modalidades de trabalhos adotados, a respeito de problemas ou dificuldades - de vários níveis encontradas.

Olh@ res, Guarulhos, v. 1, n1, p. 7-39, maio. 2013. 
âmbito de alguns seminários da universidade, especificamente projetados com este fim. Ao longo dos últimos quatro anos, foi consolidado um grupo estável de tutores que faz parte regularmente dos seminários e que está iniciando uma reflexão, articulado sobre alguns nós dessa experiência formadora e autoformadora.

Os seminários tornaram-se um lugar importante para reelaborar e compartilhar saberes entre as educadoras tutoras de creche e operam em favor de uma fruição dinâmica de conhecimento entre creches e universidade. Toma forma um espaço de elaboração totalmente peculiar, em que as educadoras tutoras de creches têm palavra para exprimir o sentido de seu envolvimento no percurso de estágio e de seu percurso pessoal de desenvolvimento profissional. São as mesmas educadoras tutoras de creche a assinalar o valor da experiência na sua formação profissional:

Eu pensei um pouco na minha experiência e me dei conta que, no final, os momentos em que aprendi mais são aqueles momentos em que havia a aprendizagem que partia da experiência, isto é, quando vivia uma coisa e depois refletia naquilo que tinha acontecido com a colega, com o tutor, mas ainda assim era uma aprendizagem que partia da experiência em que estava imersa.

Cria-se um espaço para uma metarreflexão que pode ter resultados positivos sobre a modalidade com a qual se aproxima, na prática pedagógica, a experiência educativa do estagiário e se visualiza de maneira mais aprofundada o sentido do próprio papel tutorial:

Me vem na cabeça uma diferença que faço entre "passar" e "transmitir". "Passar" vejo mais como um pacote que dou e basta, mas prefiro o termo "transmitir", que faz pensar em uma transmissão que ocorre, não digo entre modelos similares, mas entre afinidades. Recentemente tive de lidar com estagiárias com as quais havia afinidade, no sentido de que havia sintonias: você transmite alguma coisa e a outra é em fase de abertura. Há abertura, vontade de aprender, de pôr em discussão e há a leitura também do comportamento do outro que entra um pouco nos meus modos.

Os pensamentos das educadoras tutoras de creche oscilam entre a reflexão sobre a experiência tutorial em curso e as experiências educativas no âmbito do percurso profissional pessoal, em um movimento contínuo, no qual é feita referência a experiências em que se aprende e em que se sustenta a aprendizagem de outros. Emerge um conhecimento que, para usar as palavras

Olh@ res, Guarulhos, v. 1, n1, p. 7-39, maio. 2013. 
de Wenger (1998, p. 297), aponta para como "o ensino não produz a aprendizagem. Cria um contexto no qual vem a aprendizagem que também pode vir em outros contextos". Um contexto particularmente favorável, que se revelou totalmente peculiar na educação da primeira infância, é aquele da prática.

\section{Nós críticos}

A complexidade é muito elevada em um sistema educacional como aquele descrito, que implica um incessante investimento em processos de debate, divisão, mediação entre os atores que o tornam possível e que exprimem diferentes instâncias, naturalmente legítimas, mas nem sempre traduzíveis em transformações ou mudanças imediatas na complexa implementação, como gostariam. O percurso de estágio, longe de ser um caminho linear, se concretiza em um fluir movimentado de episódios, ideias, problemas, propostas, impulsos e tensões. Nessa dinâmica, tomam forma alguns nós particularmente visíveis, que sublinham elementos de crítica inerente na estrutura do projeto do estágio.

Esse nós referem-se às relações entre:

A Estagiário e tutor

A Tutor e supervisor

A Universidade e creches

\section{Estagiário e tutor}

Surgiu, a partir da descrição realizada até agora, o quanto é central a relação entre estagiário e tutor, pois é atribuído à experiência do estágio o valor assimilado pelas aprendizagens experienciais, que nascem da prática. $\mathrm{Na}$ qualidade educativa dessa relação residem condições importantes que assinalam a incisão e a significação do estágio na história da formação do estudante. Não se trata de enfatizar, por um lado, as qualidades carismáticas do orientados, suas competências formativas ou, mais complexamente, a capacidade de traduzir a expertise em benefício da aprendizagem do estagiário; nem, por outro lado, de marcar a disponibilidade, a abertura e a capacidade de envolvimento por parte

Olh@ res, Guarulhos, v. 1, n1, p. 7-39, maio. 2013. 
do estagiário. Trata-se, ao contrário, de sublinhar, em uma perspectiva dinâmica, a centralidade das condições que permitem e tornam possível um processo formador não estático e não predefinido, porque ligado à dinâmica da vida das creches e do trabalho na prática pedagógica de cada educadora tutora de creche.

Em vez das características e das específicas competências do tutor ou do estagiário, é útil, antes de tudo, questionar-se sobre quais seriam as condições para instaurar uma relação formadora entre estagiário e tutor. Isto é, se compartilhamos a posição de quem afirma que "há necessidade de uma formação que prepare desenvolver o âmbito da reflexão" (MORTARI, 2007, p. 48), então pensamos em processos nos quais a interação estagiário-tutor se torna absolutamente central, merece ser questionada e elaborada e assinala uma direção de desenvolvimento formador que inicia e se radica na prática pedagógica e no pensamento reflexivo.

Uma formação que busque preparar educadores que se situem no mundo da educação como "pesquisadores em ação" deve promover a capacidade de construir o saber a partir de sua experiência e, portanto, não pode não prever percursos objetivados a pôr os participantes na condição de adquirir a arte da reflexão. (MORTARI, 2007, p. 48).

Como se pode desenvolver a capacidade de refletir a partir da prática? Como pensar no estágio coerentemente nessa perspectiva? Não se trata, é claro, de assumir como objetivo chegar a definir percursos e estratégias padrões, formalizar em termos de critérios gerais que se uniformizam. Trata-se, sim, muito mais de conceber e testar também modos inovadores para documentar, sistematizar, dar forma conceitual às múltiplas modalidades em que, de vez em quando, essa relação formadora vem realmente com a prática pedagógica. Deve-se esclarecer bem o modo como ocorrem concretamente essas interações formadoras e em que condições se revelam eficazes. Quais elementos caracterizam positivamente estas interações? Isto é, quais são, de fato, os "percursos objetivados a pôr os participantes na condição de adquirir a arte da reflexão" a partir do envolvimento na prática educacional? Se não se trata de ensino e não se trata de pura e simples transmissão de técnicas e estratégias

Olh@ res, Guarulhos, v. 1, n1, p. 7-39, maio. 2013. 
operativas, então, de quais elementos específicos se compõe a relação formadora em que estão envolvidos um especialista e um estagiário?

Até esse momento, no percurso de estágio, não foi possível indagar de maneira direcionada e formalizada esse "objeto", de resto pouco explorado, em geral, pela pesquisa pedagógica. Mas é duvidoso que um maior conhecimento sólido nesse sentido garantisse potencializar a eficácia e a extensão dessas experiências formadoras também em contextos que não se enquadram no estágio em sentido estrito e que se referem mais diretamente à formação do corpo docente, por exemplo, na creche.

De resto, são as mesmas educadoras tutoras a assinalar tal necessidade, quando refletem sobre o estágio e descrevem alguns elementos críticos encontrados na prática pedagógica:

No início nos encontramos um pouco fora do lugar: não tinha sido definido o papel do tutor, eu fui selecionada [como tutora] porque a estagiária foi inserida na minha seção e, talvez por motivação pessoal, comecei a me colocar como referência. A própria estagiária me identificou como tutora e veio me dizer: "Mas você é a minha tutora?". Eu respondia: "Mas, não sei...". Isso nos fez refletir e, por isso, depois de dois meses, decidimos oficializá-lo. Já que tenho uma janela no horário e era também difícil achar a disponibilidade para estar com ela, decidimos fazer um acordo. Decidimos também institucionalizar com a estagiária um momento de debate semanal, porque sentíamos necessidade, ou tirar uma hora por semana para falar: "Você tira as suas necessidades, as suas dúvidas, as suas perplexidades, as coisas que vê e nós lhe contamos um pouco das coisas sobre a creche, a história."

Nessas palavras, podem ser considerados relevantes alguns fatores contextuais e organizacionais, pelo menos, internos nas creches (definição compartilhada no grupo de trabalho do tutor e legitimação institucional de seu papel, encontros regulares dedicados ao debate durante o dia, etc.). Mas depois são revelados, mais de perto, os muitos modos com que se desenvolve uma relação direcionada para a reciprocidade no curso no qual o tutor desempenha seu papel, consentindo ao estagiário pôr-se em relação crítica com os fatos observados na prática pedagógica; e, reciprocamente, o modo com que o estagiário se põe nos confrontos da realidade educacional orienta o comporta-

Olh@ res, Guarulhos, v. 1, n1, p. 7-39, maio. 2013. 
mento formador do tutor.

Mais uma vez, portanto, é enfatizado que não se trata de fixar em termos prescritivos princípios ligados ao dever ser (ser empático, valorizar os recursos de quem aprende, oferecer suporte) por parte de um e de outro participante na formação para a prática pedagógica, mas de colher um repertório de situações e experiências, também diferentes entre elas, nas quais o processo formativo na prática pedagógica tem tido sucesso, isto é, evoluiu em experiências de aprendizagem para poder conhecer os muitos modos que tornam possível aprender a partir da prática. $\mathrm{O}$ que liga as atividades e as situações em que são envolvidas as crianças, o papel do educado e a aprendizagem do estagiário?

\section{Tutor e supervisor}

Ligada a essa ordem de perguntas, coloca-se a relação tutor-supervisor, que mereceria, do mesmo modo, ser não somente melhor indagada, mas também majoritariamente sustentada e potencializada.

Até o presente momento, faltaram oportunidades para investir neste lado do percurso formador que, embora mais distante da dimensão da prática educativa, ocupa uma posição que não pode ser considerada marginal em relação aos equilíbrios complexos do projeto de estágio. É evidente que merece ser reforçada a conexão entre os processos de formação que ocorrem na prática pedagógica e aqueles que ocorrem em sala, na supervisão. E, por isso, mereceriam ser mais explícitas e partilhadas as coerências e as convergências entre as intencionalidades formadoras do tutor e aquelas do supervisor.

Antes mesmo de reforçar a partilha, põe-se, na realidade, o problema de individuar as estradas praticáveis (em termos de legitimidade institucional, de sustentabilidade econômica) para potenciar as ocasiões de projeção comum e partilha entre sujeitos que pertencem a distintas realidades organizadas e que, a título diferente, são implicadas neste projeto. Para as creches, o estágio não cai no âmbito das prioridades de intervenção e em uma situação economicamente

Olh@ res, Guarulhos, v. 1, n1, p. 7-39, maio. 2013. 
crítica como o atual, em que investe pesadamente também o mundo universitário; não é pensável que sejam destinados adequados recursos a esta frente. Esses pesados limites ameaçam a viabilidade do modelo até agora ativado, tanto rendendo, de fato, a precária figura da educadora tutora de creche, não legitimada pelas creches, bem como impedindo de implementar a colaboração do projeto entre tutores e supervisores. Essa falha, ou parcial sinergia, entre os interventores formadores joga desfavoravelmente no desenvolvimento de um fluido projeto formador realmente coerente.

As poucas ocasiões de trabalho compartilhado (basicamente apenas três encontros de grupo ao longo do curso) não podem ser consideradas suficientes; de qualquer forma, garantem ao menos ativar um nível informativo que ajuda a aliviar as recíprocas hesitações e resistências. Na verdade, por um lado, as educadoras tutoras de creche ignoram, no início, as linhas e as modalidades de desenvolvimento do projeto de estágio; e, por outro lado, nem sempre os supervisores têm um conhecimento direto do projeto pedagógico da creche e do trabalho educacional que se faz. Especificamente, em seguida, as educadoras tutoras de creche são orientadas quanto ao sentido complexo da presença do estudante que, por exemplo, não observa seu trabalho para avaliá-la a pedido da universidade, mas observa exclusivamente com a finalidade de conhecer e aprender. O foco do trabalho de supervisão não é a correção ou a qualidade do trabalho feito pela educadora, mas o processo de conhecimento e de aprendizagem do estagiário. Uma vez esclarecida esta perspectiva, pode-se abrir um terreno de colaboração que, muitas vezes, ocorre geralmente pela mediação do estagiário, que, em seu percurso, "usa" conteúdos, métodos, estratégias maturadas em, outro contexto educacional, ou seja, em sala e na creche. Nesse sentido, o tutor e o supervisor abrem perspectivas distintas - que não deveriam ser contrapostas - sobre a unilateralidade do percurso de formação que está vivendo o estagiário e lhe oferecem espaços específicos de reflexão.

A intensificação da colaboração projetada e do compartilhamento metodológico

Olh@ res, Guarulhos, v. 1, n1, p. 7-39, maio. 2013. 
entre trabalho em sala e trabalho na prática pedagógica traria, portanto, uma indiscutível potencialidade da eficácia do trabalho educacional. Isso leva a outro ponto crucial, que é ligado à natureza do projeto formador do estágio.

\section{Universidade e creches}

O planejamento global do percurso de estágio se baseia em três pressupostos centrais: na formação de base dos estudantes que aspiram tornarem-se educadores de creche, a universidade e as creches públicas expressam culturas e saberes sobre a infância que podem entrar em sinergia para uma possibilidade de compartilhar; a formação de base realizada pela universidade pode ser interpretada não setorialmente fechada em si mesma, mas com um respiro cultural mais amplo, que se desenvolve no território das creches; o saber da prática que nasce nas creches é um saber de valor assim codificado e definido teoricamente.

A partir desses pressupostos, decorreu a escolha de uma relação de colaboração com as creches para o desenvolvimento dos percursos formadores do estágio; muitos aderiram.

São evidentes os benefícios mútuos de imediato: o saber universitário pode pôrse em uma posição heurística de diálogo dinâmico com os problemas educacionais, advertidos por aqueles que operam na prática pedagógica. Dessa forma, revitalizam-se conceitos e pensamentos, preservando-os do risco de excessiva abstração, destinada à esterilidade; as creches, por sua vez, podem qualificar sua cultura pedagógica e potencializar a possibilidade de criar e difundir cultura educacional sobre a infância na região, graças à valorização dos recursos e das potencialidades profissionais internas.

Mais uma vez, a figura da educadora tutora de creche desenvolve uma função vital, que vai além do percurso de estágio: muitas vezes, age como estímulo para processos de formação e autoformação que envolvem o inteiro grupo educativo, colocando em círculo recursos, energias e disponibilidades de

Olh@ res, Guarulhos, v. 1, n1, p. 7-39, maio. 2013. 
mudança adormecidas ou bloqueadas por muito tempo. Para o grupo educativo, acolher um estudante que traz um olhar divergente em respeito ao pensamento consolidado - às vezes cristalizado - na cultura da creche, põe em discussão os modos de fazer que, por vezes, têm perdido o sentido educacional. Em suma, traz quem já trabalha na prática pedagógica a admitir um comportamento menos conformista, pondo-se criticamente em relação ao próprio modo de trabalhar. Tais resultados, muitas vezes, nem mesmo a formação conduzida intencionalmente consegue atingir.

Poderia, todavia, ser ainda mais prolífica a relação entre universidade e creches, se a atual colaboração, em geral de bases burocráticas estabelecidas por relações de convênio, se fundamentasse mais extensivamente em uma relação formalizada, planejada pela vontade estratégica de aproximar os temas da formação de base daqueles da formação em creches. Esses ambientes formadores que hoje têm vínculos e são desenvolvidos independentes revelam, na verdade, muitas linhas de conjunção e contiguidade, quando vistos na perspectiva de uma cultura pedagógica teórico-prática.

Nesse sentido, o projeto de formação de estágio, embora confirmada a titulação universitária, poderia ter um maior envolvimento projetado por parte das creches, compartilhando algumas condições de desenvolvimento centrais, como, por exemplo, a ativação de modalidades conjuntas para a escolha/seleção das educadoras tutoras; a individuação de projetos educacionais prioritários para as creches sobre as quais convergem os processos formadores do estágio, ou, também, a definição de modalidade de supervisão e suporte às funções tutoriais.

O desenvolvimento do percurso de estágio sublinha a existência de importantes recursos potenciais para explorar e experimentar, em benefício não somente do projeto formador do estágio, mas de uma cultura da infância mais forte e difundida nas creches e na região.

Olh@ res, Guarulhos, v. 1, n1, p. 7-39, maio. 2013. 


\section{Bibliografia}

AGLIATI, A. e INFANTINO, A. Fare e pensare: la formazione come cultura. In: ZANINELLI, F. L. Pedagogia e infanzia. Questioni educative nei servizi. Milano: Franco Angeli, 2010.

BRAGA, P. Promuovere consapevolezza. Esperienze di formazione tra ricerca e pratica educativa. Bergamo: Edizioni Junior, 2009.

COSENTINO, V. e SANTINI, M. (a cura di). L'amore che non scordo. Storie di comuni maestre. Milano: Libreria delle donne, 2008.

DEWEY, J. The Sources of a Science of Education. New York: Livering Publishing Corporation, 1929. Título em italiano: Le fonti di una scienza dell'educazione. La Nuova Italia, 2004.

INFANTINO, A. Progettazione pedagogica e organizzazione del servizio. Teorie e strumenti per la scuola e i servizi. Milano: Guerini, 2002.

(a cura di). Il lavoro educativo con la prima infanzia. Tra progetto pedagogico e scelte organizzative. Bergamo: edizioni Junior, 2008.

- La formazione nell'esperienza: il ruolo dell'educatrice tutor. In: BRAGA, P. Promuovere consapevolezza. Esperienze di formazione tra ricerca e pratica educativa. Bergamo: edizioni Junior, 2009.

MORTARI, L. Apprendere dall'esperienza. Il pensare riflessivo nella formazione. Roma: Carocci, 2007.

ROGOFF, B. Apprenticeship in Thinking. Cognitive Development in Social Context. Cidade: Oxford University Press, 1990. Título em italiano: Imparando a pensare. L'apprendimento guidato nei contesi culturali. Milano: Raffaello Cortina, 2006.

SCHÖN, D. A. Educative the reflective practioner. Toward a new design for teaching and learning in the professions. San Francisco: Jossey Bass, 1987. Título em italiano: Formare il professionista riflessivo. Milano: Franco Angeli, 2006.

WENGER, E. Communities of Practice, Learning, Meaning and Identity. Cambridge Olh@ res, Guarulhos, v. 1, n1, p. 7-39, maio. 2013. 
Estágio e Formação na Prática Pedagógica em Creches Públicas Italianas

University Press, 1998. Título em italiano: Comunità di pratica. Milano: Raffaello Cortina, 2006.

WOOD, D., BRUNER, J. S. e ROSS, G. The role of tutoring in problem solving. Journal of Child Psychology And Psychiatry, v. 17, p. 89-100, 1976.

Olh@ res, Guarulhos, v. 1, n1, p. 7-39, maio. 2013. 